\title{
EFFECTS OF SUSCEPTIBILTY TO INTERPERSONAL INFLUENCE ON CLOTHING BENEFITS SOUGHT
}

\author{
SYADIYAH ABDUL SHUKOR \\ Faculty of Economics and Muamalat \\ Universiti Sains Islam Malaysia
}

\begin{abstract}
Susceptibility to interpersonal influence is the tendency of an individual to be influenced by other people in their decision-making. Prior research suggests that susceptibility to interpersonal influence affects various numbers of consumer behaviours. This paper aims to investigate the effects of susceptibility to interpersonal influence on clothing benefits sought, which are: uniqueness, conformity, self-congruity, social status and modesty. Data for the present study was collected through web-based and drop off questionnaires. 222 completed questionnaires were received and analysed using the Structural Equation Modelling (SEM). Results of this study show that susceptibility to interpersonal influence is positively related to uniqueness, conformity, self-congruity and social status. Limitations and directions for future research are discussed towards the end of this paper.
\end{abstract}

Keywords: Susceptibility to interpersonal influence, clothing, clothing benefits sought.

\section{Introduction}

The purpose of this research is to investigate the effects of susceptibility to interpersonal influences on clothing benefits sought. Consumer research has long argued that interpersonal influence is an important determinant of consumer behaviours such as purchase decisions (Bearden \& Etzel, 1982), shopping behaviour (Mangleburg et al., 2004) and investment decisions (Hoffmann \& Broekhuizen, 2009). The conclusion from these studies demonstrates that consumer behaviours are subjected to consumer susceptibility to interpersonal influence.

However, a number of shortcomings in the existing literature can be identified. First, none of the study has addressed the effects of susceptibility to interpersonal influence on clothing benefits sought. 
Clothing benefits sought reflects the outcomes that clothing attributes may provide (Park \& Sullivan, 2009; Kinley, 2010) that satisfy consumer needs (Foxall Goldsmith \& Broon 1998; Sheth Newman \& Gross 1991). Consumers may adopt or purchase certain clothing for its symbolic meaning (Levy, 1959) as a means of conveying certain attributes of the self to others given that clothing is high in visual display and indicates something about the user (Holman, 1980). As such, individual susceptibility to interpersonal influence may affect consumer clothing benefits sought. Therefore, this study fills the gap in the existing literature by investigating the effects of susceptibility to interpersonal influence on five selected clothing benefits sought; uniqueness, conformity, self-congruity, social status and modesty in the context of shopping for clothing.

Second, the impact of consumer susceptibility to interpersonal influence on different groups of consumers has also been explored in previous studies, such as students and housewives (Park \& Lessig, 1977), teenagers (Mangleburg Doney \& Bristol 2004) and children (Achenreiner, 1997; Bachmann John \& Rao 1993). Furthermore, most of the previous research are North American in origin and application. To date, little research has been conducted in a specific subcultural context in which interpersonal influences make sense for consumers. Worldwide immigration patterns of recent decades have led to the creation of large ethnic minority subcultures in a number of Western countries (Cui, 1997; Jamal, 2003). In the UK, the ethnic minority community is diverse and the key ethnic minority groups (e.g. Indians, Pakistanis and etc.) originate from collectivist cultures, such as India and Pakistan (Jamal, 2003, see also Hofstede, 1981). People brought up and raised in a collectivist cultural environment are likely to be more affected by significant others (Hofstede, 1981, Mourali et al., 2005) when making clothing choices. Therefore, this research explores the role played by consumer susceptibility to interpersonal influence on the buying behaviour of clothes among one of the fastest growing ethnic subcultures in the UK, which is British Muslims.

This study develops a conceptual framework and reviews relevant literature on consumer susceptibility to interpersonal influence and clothing benefits sought when shopping for clothing. The model informs the development of a number of hypotheses. The methodology section provides the data collection procedure along with measures adopted followed by a presentation of results. A final section discusses findings and assesses implications and directions for future research. 


\section{Susceptibility to Interpersonal Influence}

Susceptibility to interpersonal influence is defined as the need to identify with or enhance one's image in the opinion of significant others through the acquisition and use of products and brands, the willingness to conform to the expectations of others regarding purchase decisions, and/or the tendency to learn about products and services by observing others or seeking information from others (Bearden, Netemeyer \& Tell 1989). Consumer susceptibility to interpersonal influence is viewed as a general trait that varies across persons and that a person's relative influenceability in one situation tends to have a significant positive relationship to his or her influenceability in a range of other social situations (Bearden et al., 1989).

Generally, susceptibility to interpersonal influence has been conceptualised into two dimensions, which are: normative and informational influence (Bearden et al., 1989; Bearden and Rose, 1990; D’Rozario, 2001). Normative influence involves a desire to conform to the expectations of the people in the group (Burnkrant \& Cousineau, 1975). A number of researchers have distinguished between two forms of normative influence: utilitarian and value expressive influence (Childers \& Rao, 1992; Burnkrant \& Cousineau, 1975). Utilitarian influence is reflected in an individual's attempt to comply with the expectations of others in order to receive rewards or avoid punishments, and it operates through the process of compliance (Burnkrant \& Cousineau, 1975; Bearden et al., 1989). Value expressive influence relates to an individual's motive to enhance or support his self-concept (Park \& Lessig, 1977). The informational dimension reflects a person's tendency to accept information from others as evidence about reality (Deutsch \& Gerard, 1955). Informational influence was found to affect product evaluation and brand selection (e.g. Burnkrant \& Cousineau, 1975; Bearden \& Etzel, 1982; Park \& Lessig, 1977) when consumers face uncertainty in decision-making.

\section{Clothing Benefits Sought}

Product is viewed as a 'bundle of benefits', or a combination of attractions that all give something of value to the customer (Hooley et al., 1998). In particular, consumers seek a variety of benefits from clothing (e.g. Shim \& Bickle, 1994; Park \& Sullivan, 2009). According to Foxall et al. (1998), benefits are whatever products provide consumers and represent the reason they want them. Benefits that consumers 
seek in products can be any kind of benefits including personal identity, body appearance and impression, social status/prestige and individuality (e.g. Park and Sullivan, 2009; Shim and Bickle, 1994). The benefits that the firm believes the product offers may not be the same as the ones the customers believe they get (Hooley Saunders \& Piercy 1998). Therefore, it is essential for marketers to understand the benefits that consumers seek from their product offerings.

Benefits sought from clothing have been studied for many years (e.g. Shim \& Bickle, 1994; Park \& Sullivan, 2009; McKinney, LegetteTaylor, Kincade \& Holloman 2004; Aiken, 1963). For instance, a study by Shim and Bickle (1994) found nine clothing benefits sought including self-improvement, social status/prestige, sex appeal, fashion image, functional/comfort, role identification, figure flaws compensation and individuality. In another study, Park and Sullivan (2009) have identified six factors; fashion, body appearance and impression, brand value, personal identity, price and comfort as the main clothing benefits sought. Kinley (2010) identified four factors of benefits sought by consumers; fashion forward, sexy, reputation, and individualist. In a qualitative study conducted by Piacentini and Mailer (2004), the authors found that clothes act as signals that the wearer is similar to other people who wear similar clothes. Other studies have demonstrated that clothes have been used to gain approval and acceptance from peers (Cox \& Dittmar, 1995), as direct expression of one's self-concept (Goldsmith, Flynn \& Moore 1996; Goldsmith, Moore \& Beaudion 1999), personality, occupational status, and affiliation with a group (Horn \& Gurel, 1981). Results from these studies suggest that consumers seek different types of benefits from purchasing clothing from functional benefits or utilitarian purposes (i.e. price and clothing material) to expressing consumers' personality, social status or affiliation or to fulfil their psychological and emotional needs.

The impact of the individual's susceptibility to interpersonal influence on product-and brand-purchase decisions has received considerable attention (Batra, Homer \& Kahle 2001; Orth \& Kahle, 2008; Bearden \& Etzel, 1982). For instance, Batra et al. (2001) found that high susceptibility to normative influence leads to a greater importance for those product attributes that provide socially visible benefits (i.e. reputation and style). By extending Batra et al.'s (2001) work from product attributes to brand benefits, Orth and Kahle (2008) showed that more susceptibility to normative influence tends to exhibit a desire for social benefit in a brand since they have a higher need to enhance their image in the opinion of others and tend to conform 
more to the expectations of others. The findings from both studies (Orth \& Kahle, 2008; Batra et al., 2001) are consistent with the study by Bearden and Etzel (1982) which shows that reference group influence on a product-and brand-purchase decision is stronger for product consumed publicy as compared to product consumed privately.

It appears that consumer consumption is strongly influenced and shaped by reference group influence and individual proneness to interpersonal influences. In particular, interpersonal influence on consumer consumption is stronger for products consumed publicly (Bearden \& Etzel, 1982). This could be happening because products consumed publicly (such as clothing) can be associated with the personal characteristics of their users more than those products that are consumed in private. However, to the best of our knowledge, no prior research has investigated the impact of consumer susceptibility to interpersonal influence on clothing benefits sought in the context of shopping for clothing by British Muslim consumers.

\section{Conceptual Framework and Research Hypotheses}

Figure 1 presents the conceptual framework developed in this study. The conceptual framework suggests that consumer susceptibility to interpersonal influence affects clothing benefits sought which is identified by five constructs namely uniqueness, conformity, selfcongruity, social status and modesty.

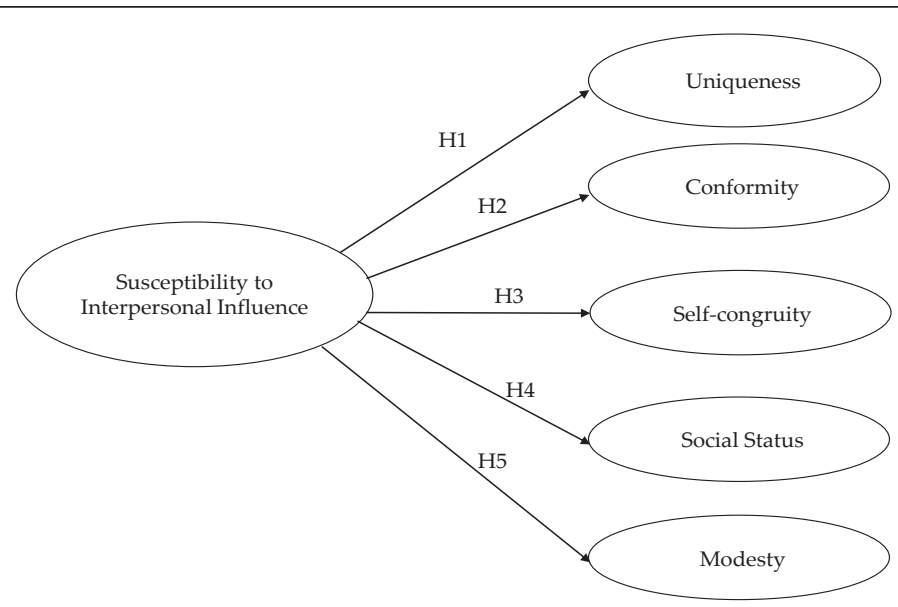

Figure 1. Conceptual framework and research hypotheses. 
Consumers may acquire and display material possession for the purpose of feeling differentiated from other people (Tian, Bearden \& Hunter 2001). In the context of clothing, individuals tend to buy clothes as enhancement of individuality (Barnard, 1996). According to Tian et al. (2001), consumers seeking uniqueness in products or brands is indicative of an enduring personality trait referred to as "consumer need for uniqueness" or CNFU, which is defined as an individual's pursuit of differentness relative to others that is achieved through the acquisition, utilisation and disposition of consumer goods for the purpose of developing and enhancing one's personal and social identity. Consumers seeking for uniqueness tend to select products and brands that differ from established norms, avoid similarities, and make choices that position the individual as distinct from the group (Tian et al., 2001).

Research has shown that being susceptible to interpersonal influence from another implies that others' opinions and evaluations are important. Whether others' opinions provide evidence about reality or serve to maintain or enhance the individual's self-esteem, the consumer has significant others who can help meet his/her informational and social (normative) needs (Bearden et al., 1989). Logically, people who tend to place importance on uniqueness benefit are not concerned about social acceptance as they are actively avoiding compliance with established social norms (Tian et al., 2001). Thus, they are not subject to social influence. As such, individuals who are more susceptible to interpersonal influence; who have higher needs to enhance their image in the opinion of others and a high tendency to conform to the expectations of others (Bearden et al., 1989) may not seek uniqueness benefits in their purchase. In other words, consumers seeking uniqueness through their purchase actively seek to separate themselves from established social norms. As such, individuals who are less susceptible to interpersonal influence should place more value on uniqueness benefit as they need to enhance their individuality through clothing. In contrast, individuals with high susceptibility to interpersonal influence would place lesser value on uniqueness benefits when purchasing clothes. This suggests a negative relationship between the two constructs. It is thus hypothesised that:

H1: Consumer susceptibility to interpersonal influence is negatively related to uniqueness benefit in clothing.

Previous research shows that consumers may purchase clothes for conformity benefit (Aiken, 1963) so that they can be accepted by 
the group they wish to be associated with (MacGillivray \& Wilson, 1997). According to Kahle (1995), tendency to conform or conformity motivation relates to consumer's concern with adhering to group norms in purchase decision of a product or brand. In the context of clothing, conformity means acceptance or adherence to a clothing norm, that is, dressing in accordance with the norm of a specified group (Horn \& Gurel, 1981). Therefore, the desire to conform appears to be affected by the norms of society.

Susceptibility to interpersonal influence reflects an individual willingness to comply with the wishes of others (normative influence) and the willingness to accept and internalise information from others (informational influence) (Bearden et al., 1989). Following this, it is expected that individuals with high susceptibility to interpersonal influence would place more importance on conformity benefit in buying clothing as they have a higher tendency to conform to other's expectations and higher needs to identify with or enhance one's image in the opinion of significant others through the acquisition and use of products and brands (Bearden et al., 1989). On the other hand, individuals who are less susceptible to interpersonal influence would place lesser importance on conformity benefit when purchasing clothes because they are not concerned with conforming to group norms and it will be reflected in their product choice. Thus, the following hypothesis is established:

H2: Consumer susceptibility to interpersonal influence is positively related to conformity benefit in clothing.

When making decisions in purchasing a product, a customer will not only consider its functional features, but also attempt to comply with the preference of others and present himself/herself to others through the purchase (Johar \& Sirgy, 1991). Consumers hold images of themselves, of products, and of the types of consumers who purchase and use certain products. The relationship between selfimage and product-image can have significant effects on consumers' product evaluations and purchase behaviours. In the context of clothing, consumers may purchase clothes that have images similar to their own self-image and typical images of consumers who purchase and use those clothes. The idea of consumers preferring brands that have images similar to their own self-image is known as selfcongruity (Sirgy, 1982, Sirgy et al., 1997) and it is an important factor in directing consumer preference and choice (Heath \& Scott, 1997; Kleijnen, Ruyter \& Andreassen 2005; Sirgy et al., 1997). 
Studies conducted by Escalas and Bettman (2003) and Jia et al. (2007) reveal that reference groups can significantly influence an individual's self-brand connection; which measures the degree to which consumers have incorporated the brand into their self-concept. Escalas and Bettman's (2003) study shows that respondents are more likely to develop self-brand connections when there is a strong perceived usage association between the member group and the brand and there is a strong connection between the member group and the consumer's self-concept. In a later study, Jia, Wang \& Lui (2007) stated that the more an individual is subjected to normative (utilitarian and value expressive) reference group influence, the more the individual tends to pursue the congruency between selfconcept and the image a brand symbolises. The findings show that interpersonal influence impacts on an individual's need for selfcongruity. This is particularly relevant in the context of clothing as the product has been used as an instrument in improving self-concept through transferring socially attributed meanings of the product or brand to oneself (Grubb \& Stern, 1971). In other words, the social meaning attached to clothes lead individuals to use them to express themselves. As a consequence, consumers would be able to maintain and enhance their personality and self-concept (Hong \& Zinkhan, 1995) and receive positive evaluation from significant others. As such, an individual who is concerned with other people's opinions may place importance on self-congruity benefit when purchasing clothes and would observe other people's clothing styles. In contrast, less susceptible to interpersonal influence individuals are less concerned with this benefit as they do not behave according to social expectations. Thus, the following hypothesis is established:

H3: Consumer susceptibility to interpersonal influence is positively related to self-congruity benefit in clothing.

Consumers may seek social status benefit when purchasing clothes as it is often used to indicate social worth or status and people often make judgments concerning other people's social worth or status on the basis of what those people are wearing (Barnard, 1996). As such, social influence does have an impact on consumer needs for social status benefit in clothing. Social influence can be in the form of normative or informational influence (Burnkrant \& Cousineau, 1975; Deutsch \& Gerard, 1955). Informational influence which reflects the tendency to accept information from others as reality can result from either a search for information from others who are considered knowledgeable or from the observation of others' behaviour (Park \& 
Lessig, 1977). Thus, it is likely that consumers seeking for social status benefit in clothing are keen to observe cues associated with status within a group and would be more susceptible to informational influence within the group. In addition, consumers who place importance on social status benefit would engage in conversations with members of their reference groups about prestige and status associated with certain products and brands.

On the other hand, normative influence which reflects an individual's willingness to comply with the wishes of others (Burnkrant \& Cousineau, 1975) consists of value expressive and utilitarian influences (Bearden et al., 1989; Childers \& Rao, 1992). Park and Lessig (1977) describe value expressive influence as conformity with the behaviours or opinions of others in an effort to align one's self-image with another individual or with members of a reference group and utilitarian influence is an individual orientation toward conformity as a means to avoid punishment and/or reap rewards. Therefore, consumers seeking social status benefit see products as a vehicle to enhance their social image within the group and view status within a reference group as a reward that results from the purchase of products that convey prestige and status. Moreover, normative influence of the group defines which products and brands are prestigious. This susceptibility also reflects a person's need to identify or enhance one's image with significant others through material possessions (Bearden et al., 1989). In view of that and the above discussion, it is likely that a consumer seeking social status benefit is influenced by both interpersonal influence pressures. Hence, the following hypothesis is established:

H4: Consumer susceptibility to interpersonal influence is positively related to social status benefit in clothing.

Consumers may seek modesty benefit; the fundamental basis for all clothing (Barnard, 1996; Horn \& Gurel, 1981). Modesty revolves around the idea that certain body parts are indecent or shameful and should be covered so that they cannot be seen (Barnard, 1996). In Islam, Muslims are required to dress modestly whereby clothing should not be worn for the purpose of attracting attention or showing off. Clothing must be loose and cover the entire body; only the hands and face may remain visible for women. Material used to cover the body parts is thick so that no one can see through it. The women's clothing must not resemble the men's clothing, nor should the man's clothing resemble the women's and Muslims should not wear clothing to look like a non-Muslim (Badawi, 1980). 
Muslims are required to dress modestly so that attention is not drawn to the wearers. Prophet Muhammad says, "Whoever wears a dress of fame in this world, all will clothe him with a dress of humiliation on the day of resurrection, then set it afire". This Hadith shows that clothing should not be worn for the purpose of attracting attention or to show off. Muslims are not supposed to emphasise their body and should wear clothes that discreetly cover it (Iqbal, 1973). Therefore, people seeking modesty benefit in clothing do not wish to display and enhance the sexual or social attractiveness of themselves in the eyes of other people. This implies that they are not concerned with conforming to the social expectation and may choose certain clothes not because other people would observe them. In view of that, individuals who place importance on modesty benefit in clothing would be less concerned with other people's opinions as their motives of clothing are not to draw other people's attention to them or for the purpose of showing off. In contrast, people who place less importance on this benefit may be more susceptible to other people's expectations and thus the following hypothesis is developed:

H5: Consumer susceptibility to interpersonal influence is negatively related to modesty benefit in clothing.

\section{Methodology}

\section{Sampling and Data Collection}

The data collection process was conducted over a period of 6 weeks. A total of 222 survey questionnaires were received. 82.6\% were from females and $17.4 \%$ were from males. The information on the marital status of the respondents demonstrated that more than half $(78.2 \%)$ were single, followed by married/living with partners $(19.9 \%)$ and divorced $(1.9 \%)$. With regards to educational background, the majority of the respondents had obtained undergraduate degrees (53.4\%). While others had attended at least high school and obtained equivalent to GCSEs/O Level (5.4\%), A Levels (17.6\%), professional qualification/diploma (10.3\%), and postgraduate degrees (13.2\%).

The demographic profile of the respondents matched the profile of British Muslims in UK (UK National Statistics, 2001). According to the UK National Statistics (2001), three quarters (74\%) of Muslims were from an Asian ethnic background, predominantly Pakistani (43\%), Bangladeshi (16\%), Indian (8\%) and other Asians (6\%). In this 
study, in terms of the ethnic group, the majority of the respondents associated themselves with Pakistan (40\%), Bangladesh (14\%) and India $(12.1 \%)$. Therefore, it can be concluded that the data represented the population.

\section{Survey Instrument}

The measures pertaining to uniqueness, conformity, self-congruity, social status, modesty and susceptibility to interpersonal influence were measured by asking respondents questions in the form of a 7-point Likert scale ranging from ' 1 ' (strongly disagree) to ' 7 ' (strongly agree). Uniqueness was measured using four items adapted from Gurel and Gurel (1979) and Park and Sullivan (2009). The conformity scale was measured using five items adapted from Gurel and Gurel (1979) while self-congruity was measured using five items adapted from Sirgy et al. (1997). Five items to measure social status were adapted from Eastman et al. (1999) and Summer et al. (2006) and the modesty scale was measured using six items adapted from Gurel and Gurel (1979). Finally, the scale for susceptibility to interpersonal influence was measured using 12 items adapted from Bearden et al. (1989). The survey questionnaire items were pretested on a sample of 35 British Muslims.

\section{Findings and Discussion}

\section{Construct Validity}

The construct validity for all the measures was assessed before assessing the hypothesized relationships shown in Figure 1. First, the exploratory factor analysis was performed for each construct and the results revealed that the data were appropriate factor analysis. Most of the correlation coefficients were above 0.3, the Kaiser-Meyer-Oklin Measure of Sampling Adequacy (KMO) value was higher than the recommended value of $0.6(0.873)$ and the Bartlett's Test of Sphericity achieved statistical significance confirming the suitability of the data for factor analysis (Pallant, 2005).

Having conducted the EFA analysis for all the constructs, the validity and reliability tests were conducted using the confirmatory factor analysis. The results showed $\mathrm{x}^{2}$ value of 356.605 with 254 degrees of freedom ( $p=0.000)$ and demonstrated good-of-fit indices (CFI=0.967, $\mathrm{TLI}=0.961, \mathrm{RMSEA}=0.043$, and $\left.\mathrm{x}^{2} / \mathrm{df}=1.404\right)$. All standardised loadings 
were above 0.5 and construct reliability for all constructs were greater than 0.8, which exceeded the suggested value of 0.6 (Hair, Black, Babin, Andersoon \& Tatham 2006). In addition, variance extracted satisfied the recommended value of 0.5. Therefore, the CFA results for overall constructs exhibited satisfactory results with regard to the fit indices, unidimensionality, convergent validity, discriminant validity and reliability. This suggests that the values were sufficient to confirm a good fit of the model to the data.

\section{Structural Model}

The results of the full strutcural model is presented in Table 1. The fit indices (CFI $=0.965$, TLI $=0.961$, RMSEA $=0.043, \mathrm{x}^{2} / \mathrm{df}=1.402$ ) are acceptable, which implies that the estimated model has achieved a good fit. Susceptibility to interpersonal influence showed signifcant effects on uniqueness (0.345), conformity (0.730), self-congruity (0.483) and social status (0.76). Results do not support the relationship between modesty and suscpetibility to interpersonal influence. Thus, $\mathrm{H} 1, \mathrm{H} 2, \mathrm{H} 3$ and $\mathrm{H} 4$ are accepted while $\mathrm{H} 5$ is rejected. Susceptibility to interpersonal influence as a factor consisted of normative and informational influence. Loading of normative influence on susceptibility to interpersonal influence is 0.894 whereas the loading of informational influence on susceptibility to interpersonal influence is 0.598 .

Table 1

Structural Model Results

\begin{tabular}{llccc}
\hline \multicolumn{1}{c}{$\begin{array}{c}\text { Hypotheses and Hypothesed and } \\
\text { Paths }\end{array}$} & $\begin{array}{c}\text { Standardised } \\
\text { Coefficients }\end{array}$ & $\begin{array}{c}\text { Critical Ratio } \\
\text { (t-value) }\end{array}$ & Results \\
\hline H1 & $\begin{array}{l}\text { Susceptibility to Interpersonal } \\
\text { Influence à Uniqueness }\end{array}$ & 0.345 & $4.037^{* * *}$ & Supported \\
H2 & $\begin{array}{l}\text { Susceptibility to Interpersonal } \\
\text { Influence à Conformity }\end{array}$ & 0.730 & $8.158^{* * *}$ & Supported \\
H3 $\quad \begin{array}{l}\text { Susceptibility to Interpersonal } \\
\text { Influence à Self- congruity }\end{array}$ & 0.483 & $5.734^{* * *}$ & Supported \\
H4 $\quad \begin{array}{l}\text { Susceptibility to Interpersonal } \\
\text { Influence à Social Status }\end{array}$ & 0.076 & $9.178^{* * *}$ & Supported \\
H5 $\quad \begin{array}{l}\text { Susceptibility to Interpersonal } \\
\text { Influence à Modesty }\end{array}$ & -0.053 & $-0.694(\mathrm{NS})$ & Rejected \\
\hline
\end{tabular}

(continued) 


\begin{tabular}{llc}
\hline Goodness-of-fit Statistics & Results \\
\hline Absolute fit & Chi square $\left(x^{2}\right)$ of estimate model & $x^{2}=375.85$ \\
& & $\mathrm{df}=268$ \\
& $\mathrm{p}=0.000$ \\
& Root Mean Square Error of Approximation & 0.043 \\
& (RMSEA) & \\
Incremental fit & Tucker Lewis Fit (TLI) & 0.961 \\
& Bollen's Incremental Fit Index (IFI) & 0.966 \\
& Comparative Fit Index (CFI) & 0.965 \\
Parsimonious fit & Parsimony fit ( $x^{2} /$ df) & 1.402 \\
& Parsimony Normed Fit Index (PNFI) & 0.795 \\
& Parsimony Goodness-of-fit Index (PGFI) & 0.730 \\
\hline
\end{tabular}

${ }^{* * *}$ significant at $\mathrm{p}<0.001$, NS-not significant.

The result of Hypothesis 1 is in line with expectation except that the sign of the relationship shows a reverse direction. It was expected that the British Muslim consumer's susceptibility to interpersonal influence is negatively related to the uniqueness benefit in clothing. However, the research findings show that British Muslim consumer's susceptiblity to interpersonal influence enhances their need for uniqueness in clothing. The positive link between susceptibility to interpersonal influence and the need for uniqueness is perhaps related to the context of this study. Because this study is conducted in a Western culture, having a unique identity via clothing appears to exhibit desirable attributes since the culture emphasises individuality, personal success, originality and uniqueness when compared to Eastern cultures which value group benefits, harmony, and family integrity (e.g. Burns \& Brady, 2001; Lee \& Kacen, 2000). Therefore, the respondents' need for uniqueness in the context of clothing may have helped to reinforce British Muslims' cultural and religious identities. Consequently, exhibiting uniqueness via clothing may have allowed these relatively young British Muslims to win social appreciation and a sense of assimilation.

The results of Hypothesis 2 support the positive link between British Muslim consumers' susceptibility to interpersonal influence and conformity benefits in clothing. This means that the more susceptible a consumer's toward interpersonal influence, the more likely he or she is to place importance on conformity benefit in clothing. Support for the positive relationship between susceptibility to interpersonal influence and conformity benefit in clothing may indicate that relatively young British Muslims in this study are able to maintain standards or norms as set by a specified group through wearing 
dress similar to their respective social groups. It can also be said that wearing or adopting similar styles worn by the group members may have created a unified look or image with the group that they want to be identified with.

The result of Hypothesis 3 is in line with expectation. It suggests that the more susceptibile individuals are toward interpersonal influence the more they are likely to purchase clothing that show a higher degree of congruence between the individual's self image and product- user image (Sirgy et al., 1997). This finding is consistent with the results found by Jia et al. (2007) that show that the more an individual subject is to normative (utilitarian and value expressive) reference group influence, the more the individual tends to pursue the congruency between the self-concept and the image a brand symbolises.

The finding of Hypothesis 4 is in line with expectation. The results of this study suggest that there is an important impact of interpersonal influence on consuming clothing for social status purpose. Consumers are motivated to acquire products according to what they mean to them and to the other members of their social reference groups (Leigh \& Gabel, 1992). Consequently, it would appear that consumption of clothing for social status is considered appropriate among the relatively young British Muslim's social environment, which in turn makes them undertake such behaviour in order to fit the social standards (Shukla, 2010). Thus, it can be said that the British Muslims' desire for social status through clothing is determined by social network and reference group influence (Wong \& Ahuvia, 1998). As such, the direct positive link between susceptibility to interpersonal influence and social status in clothing suggests that the British Muslim's motivation to improve their social standing via consumption of clothing products was enhanced by their tendency to accept social influence.

The result of Hypothesis 5 is not significant although it shows negative relationship between modesty and susceptibility to interpersonal influence. An explanation for the contrary result of Hypothesis 5 can be found in the demographic profile of the sample. Given that the British Muslim sample in this study comprised of young people between the ages of 18 and 30, it can be assumed that they placed less importance on dressing modestly. Drake (1978), cited in Horn and Gurel (1981), found that concern with modesty in clothing may also change with age where by the younger age group expressed 
little concern about the degree of body exposure or tightness of clothing compared to the elder people. This finding implies that the importance of wearing modest clothing is less important among young people. Other than that, the majority $(72.8 \%)$ of the British Muslim sample in this study have been in the UK since they were born, and presumably have adopted host country attitudes and values (Penaloza, 1994). In terms of consumption, they are more likely to show preference for mainstream products (Laroche et al., 1999; Green, 1997). Consequently, their way of dressing might depict the typical westeners' clothing which includes short skirts, tight trousers, shorts and tops. Accordingly, in this study, individual susceptibility to interpersonal influence is not related to an individual's need for modesty in clothing.

\section{Limitations and Directions for Future Research}

The results obtained from this empirical work must be interpreted in the light of the study's limitations. In this study, analysis was restricted to a particular product context (e.g., clothing) and consumer segment (e.g., British-Muslims) and needs to be tested over numerous contexts before one can be certain of its applicability to other domains. In this study the data was collected through web-based questionnaires, whereby the respondents were asked to complete the questionnaire on their own. This method was employed because errors in the coding of answers could be avoided (Bryman \& Bell, 2007) but, on the other hand, the respondents might fill out the questionnaire arbitrarily.

Despite its limitations, the findings of this study provide a platform for future investigation and it yields valuable insights into the importance of a number of marketing issues. First, the results of this study are limited to a relatively young British Muslim population aged between 18 and 30 years old. This study could be replicated for British Muslims in other age categories (i.e. teenagers or adults above 30 years old). Such studies would ensure that the findings of this study are not limited to just one specific age category but indeed reflect a more general relationship. Therefore, it is suggested that future research endeavours should include different age categories. Further research may also benefit by a broadening of the scope of examination to include other ethno-religious minorities (such as Hindus, Buddhists and Sikhs) as this study is limited to British Muslims. This will provide finer and more meaningful categories for marketers (Sirkeci, 2009). 


\section{References}

Achenreiner, G. B. (1997). Materialistic values and susceptibility to influence in children. Advances in Consumer Research, 24, 82-88.

Aiken, L. R. (1963). The relationships of dress to selected measures of personality in undergraduate women. The Journal of Social Psychology, 59, 119-128.

Bachmann, G. R., John, D. R., \& Rao, A. R. (1993). Children's susceptibility to peer group purchase influence: An exploratory investigation. Advances in Consumer Research, 20, 463-468.

Badawi, J. A. (1980). The status of woman in Islam [Online]. Retrieved from www.al-islamforall.org

Barnard, M. (1996). Fashion as communication. London: Routledge.

Batra, R., Homer, P. M., \& Kahle, L. R. (2001). Values, susceptibility to normative influence, and attribute importance weights: A nomological analysis. Journal of Consumer Psychology, 11, 115 -128 .

Bearden, W. O., \& Etzel, M. J. (1982). Reference group influence on product and brand purchase decisions. Journal of Consumer Research, 9, 183-194.

Bearden, W. O., Netemeyer, R. G., \& Teel, J. E. (1989). Measurement of consumer susceptibility to interpersonal influence. Journal of Consumer Research, 15, 473-481.

Bearden, W. O., \& Rose, R. L. (1990). Attention to social comparison information: An individual difference factor affecting consumer conformity. Journal of Consumer Research, 16, 461-471.

Burnkrant, R. E., \& Cousineau, A. (1975). Informational and normative social influence on buyer behavior. Journal of Consumer Research, 2, 206-215.

Childers, T. L., \& Rao, A. R. (1992). The influence of familial and peer-based reference groups on consumer decisions. Journal of Consumer Research, 19, 198-211.

Cox, J., \& Dittmar, H. (1995). The functions of clothes and clothing (dis)satisfaction: A gender analysis among British students. Journal of Consumer Policy, 18, 237.

Cui, G. (1997). Marketing strategies in a multi-ethnic environment. Journal of Marketing Theory and Practice, Winter, 122-134.

D'Rozario, D. (2001). The structure and properties of the consumer susceptibility to interpersonal influence scale in two immigrant populations in the U.S. Journal of International Consumer Marketing, 13, 77-101.

Deutsch, M., \& Gerard, H. (1955). A study of normative and informational social influences upon individual judgment. Journal of Abnormal and Social Psychology, 51, 624-636. 
Drake, D. (1978). Clothing interests of young adult, middle aged, and elderly men (Unpublished doctoral dissertation). Virginia Polytechnic Institute and State University.

Eastman, J. K., Goldsmith, R. E., \& Flynn, L. R. (1999). Status consumption in consumer behavior: Scale development and validation. Journal of Marketing Theory and Practice, 7, 41.

Escalas, J. E., \& Bettman, J. R. (2003). You are what they eat: The influence of reference groups on consumers' connections to brands. Journal of Consumer Psychology, 13, 339-348.

Foxall, G. R., Goldsmith, R. E., \& Brown, S. (1998). Consumer psychology for marketing. London: International Thomson Business Press.

Goldsmith, R. E., Flynn, L. R., \& Moore, M. A. (1996). The self concept of fashion leaders. Clothing and Textiles Research Journal, 14.

Goldsmith, R. E., Moore, M. A., \& Beaudoin, P. (1999). Fashion innovativeness and self concept: A replication. Journal of Product and Brand Management, 8, 7-18.

Green, C. L. (1997). In-store vs. out-of-store coupons: An examination of Anglo-, African-, and Hispanic-American redemption. Journal of Marketing Theory and Practice, 5, 113.

Grubb, E. L., \& Stern, B. L. (1971). Self concept and significant others. Journal of Marketing Research, VIII, 382-385.

Gurel, L. M., \& Gurel, L. (1979). Clothing interest: Conceptualization and measurement. Home Economics Research, 7, 274-282.

Hair, J. F., Black, W. C., Babin, B. J., Anderson, R. E., \& Tatham, R. L. (2006). Multivariate data analysis. Delhi, India: Pearson Education.

Heath, A. P., \& Scott, D. (1997). The self concept and image congruence hypothesis-an empirical evaluation in the motor vehicle market. European Journal of Marketing, 32, 110-1123.

Hoffmann, A. O. I., \& Broekhuizen, T. L. J. (2009). Susceptibility to and impact of interpersonal influence in an investment context. Journal of the Academy Marketing Science, 37, 488-503.

Hofstede, G. (1981). Culture and organizations. International Studies of Management and Organization, 10, 15-41.

Holman, R. H. (1980). Clothing as communication: An empirical investigation. Advances in Consumer Research, 7, 372-377.

Hong, J. W., \& Zinkhan, G. M. (1995). Self concept and advertising effectiveness: The influence of congurency, conspicuousness and response. Psychology \& Marketing, 12, 53.

Hooley, G. J., Saunders, J. A., \& Piercy, N. F. (1998). Marketing strategy and competitive positioning. London: Prentice Hall Europe.

Horn, M. J., \& Gurel, L. M. (1981). The second skin. Boston, London: Houghton Mifflin. 
Iqbal, M. (1973). The way of the Muslim. Ammersham, Buckinghamshize: Hulton Educational Publications.

Jamal, A. (2003). Marketing in a multicultural world: The interplay of maketing, ethnicity and consumption. European Journal of Marketing, 37, 1599.

Jia, H., Wang, Y., \& Liu, J. (2007). Reference group influence on desired self brand congruency in mobile phone purchasing behaviors-an empirical study in China. A paper presented on the International Conference on Wireless Communications, Networking and Mobile Computing at Shanghai, China on 21-25 September 2007.

Johar, J. S., \& Sirgy, M. J. (1991). Value-expressive versus utilitarian advertising appeals: When and why to use which appeal. Journal of Advertising, 20, 23-33.

Kahle, L. R. (1995). Observations: Role relaxed consumers: Empirical evidence. Journal of Advertising Research, 35, 59-62.

Kinley, T. (2010). Fit and shopping preferences by clothing benefits sought. Journal of Fashion Marketing and Management, 14, 397411.

Kleijnen, M., Ruyter, K. D., \& Andreassen, T. W. (2005). Image congruence and the adoption of service innovations. Journal of Service Research, 7, 343-359.

Laroche, M., Kim, C., \& Tomiuk, M. A. (1999). Italian ethnic identity and its relative impact on the consumption of convenience and traditional foods. British Food Journal, 101, 201.

Levy, S. J. (1959). Symbols for sale. Harvard Business Review, 37, 117124.

Macgillivray, M. S., \& Wilson, J. D. (1997). Clothing and appearance among early, middle and late adolescents. Clothing and Textiles Research Journal, 15, 43-49.

Mangleburg, T. F., Doney, P. M., \& Bristol, T. (2004). Shopping with friends and teens' susceptibility to peer influence. Journal of Retailing, 80, 101-116.

Mckinney, L., Legette-Taylor, D., Kincade, D., \& Holloman, L. (2004). Selected social factors and the clothing buying behaviour patterns of black college consumers. The International Review of Retail, Distribution and Consumer Research, 14, 389-406.

Mourali, M., Laroche, M., \& Pons, F. (2005). Individualistic orientation and consumer suceptibility to interpersonal influence. The Journal of Services Marketing, 19, 164-173.

Orth, U. R., \& Kahle, L. R. (2008). Intrapersonal variation in consumer susceptibility to normative influence: Toward a better understanding of brand choice decisions. Journal of Social Psychology, 148, 423-448. 
Pallant, J. (2005). SPSS survival manual: A step by step guide to data analysis using SPSS for Windows (Version 12). London, United Kingdom: Open University Press.

Park, C. W., \& Lessig, V. P. (1977). Students and housewives: Differences in susceptibility to reference group influence. Journal of Consumer Research, 4, 102-110.

Park, H.-H., \& Sullivan, P. (2009). Market segmentation with respect to university students' clothing benefits soughtshopping orientation, clothing attribute evaluation, and brand repatronage. International Journal of Retail \& Distribution Management, 37, 182-201.

Penaloza, L. (1994). Atravesando Fronteras/border crossings: A critical ethnographic exploration of the consumer acculturation of Mexican immigrants. Journal of Consumer Research, 21, 32-54.

Piacentini, M., \& Mailer, G. (2004). Symbolic consumption in teenagers' clothing choices. Journal of Consumer Behaviour, 3, 251-262.

Sheth, J. N., Newman, B. I., \& Gross, B. L. (1991). Why we buy what we buy: A theory of consumption values. Journal of Business Research, 22, 159-170.

Shim, S., \& Bickle, M. C. (1994). Benefit segments of the female apparel market: Psychographics, shopping orientations and demographicSirgy, M. J. (1982). Self-concept in consumer behavior: A critical review. Journal of Consumer Research, 9, 287-300.

Sirgy, M. J., Grewal, D., Mangleburg, T. F., Park, J.-O., Chon, K.-S., Claiborne, C. B., Johar, J. S., \& Berkman, H. (1997). Assessing the predictive validity of two methods of measuring self-image congruence. Journal of the Academy of Marketing Science, 25, 229.

Summer, T. A., Belleau, B. D., \& Xu, Y. (2006). Predicting purchase intention of a controversial luxury apparel product. Journal of Fashion Marketing and Management, 10, 405-419.

Tian, K. T., Bearden, W. O., \& Hunter, G. L. (2001). Consumers' need for uniqueness: Scale development and validation. Journal of Consumer Research, 28, 50-66.

Uk National Statistics. 2001. Focus on religion [Online]. Retrieved from http://www.statistics.gov.uk 